\title{
PICHO-AÇÃO: A CONSTRUÇÃO DISCURSIVA DO PICHO NA CIDADE DE SANTA MARIA/RS
}

\section{THE DISCURSIVE CONSTRUCTION OF GRAFFITI IN THE CITY OF SANTA MARIA/RS}

\author{
Noara Bolzan Martins ${ }^{36}$ \\ Themis Karine Dutra Menegazzi ${ }^{37}$
}

\begin{abstract}
RESUMO: Este estudo tem como propósito analisar a construção discursiva do picho, presente no centro da cidade de Santa Maria/RS. Entendemos que essa proposta justifica-se por promover o estudo dos chamados discursos marginais e de uma importante e comum intervenção visual no espaço urbano, que é o picho. Esta análise foi realizada a partir da Análise Crítica do Discurso e do modelo tridimensional do discurso (FAIRCLOUGH, 2001). Percebemos o foco dado, no discurso do picho, para a ação em direção à mudança social. O picho, expressão artística subversiva e transgressora, rearticula discursos ideologicamente naturalizados, estabelecendo uma luta hegemônica em prol das minorias.
\end{abstract}

PALAVRAS-CHAVE: Discurso. Mudança Social. Picho.

ABSTRACT: This study aims to analyze the discursive construction of graffiti, in the center of the city of Santa Maria / RS. We understand that this proposal is justified by promoting the study of the so-called marginal speeches and of an important and common visual intervention in the urban space, which is the graffiti. This analysis was performed from the Critical Discourse Analysis and the three-dimensional discourse model (FAIRCLOUGH, 2001). We perceive the focus given, in the speech of the itch, for action toward social change. The graffiti, subversive and transgressed artistic expression, rearticulates ideologically naturalized discourses, establishing a hegemonic struggle in favor of minorities.

KEYWORDS: Speech. Social Change. Graffiti.

\section{Introdução}

Como sujeitos pertencentes a uma sociedade, temos a necessidade de compreender as dimensões ideológicas e hegemônicas que guiam nossos discursos nas mais diversas práticas. A prática de pichação, produção do picho, está bastante presente na sociedade e vem gerando polêmica, sobretudo, desde o século XX. Há uma visão dicotômica sobre o movimento, no qual, de um lado, é considerado como representação cultural e artística, e, de outro, é visto como vandalismo e depredação.

Um acontecimento muito noticiado na mídia foi a invasão da 28. ${ }^{a}$ Bienal de São Paulo por pichadores no dia da abertura em $2008^{38}$. Foram pichadas frases como "Isso que é arte", problematizando a visão negativa dada ao movimento. O questionamento sobre o conceito de arte foi intensificado com a descriminalização do Grafite em 2011, fato que o promoveu como forma de arte, enquanto o picho seguiu com sua carga negativa.

Ainda, recentemente, no final do ano de 2016, o assunto voltou com força à mídia devido à pichação de monumentos em São $\mathrm{Paulo}^{39}$. O ato foi encarado como violência a umas das principais obras artísticas do país. Contudo, houve um grupo que considerou a existência

\footnotetext{
36 Mestre em Linguística (UFSM). Professora do Departamento de Letras (UFN). E-mail: noarabolzan@gmail.com

${ }^{37}$ Licenciada em Letras -Língua Portuguesa e Língua Inglesa (UFN). Estudante de especialização em Gestão Educacional (UFSM). E-,mail: themismenegazzii@gmail.com

${ }^{3}$ Fonte Jornal Estadão. Disponível em http://cultura.estadao.com.br/noticias/geral,bienal-sofre-ataque-de-40pichadores-no-dia-da-abertura,267070. Acesso em 01/06/2017.

39 Fonte Jornal G1. Disponível em http://g1.globo.com/sao-paulo/noticia/2016/09/monumentos-amanhecempichados-com-tinta-colorida-em-sp.html Acesso em 01/06/2017.
} 
de monumentos como violência, homenageando bandeirantes que, na verdade, era um grupo de supostos assassinos do povo indígena.

Por fim, o acontecimento crucial que fixou o grafite e, por consequência, o picho como tema de frequentes reportagens e debates, foi o apagamento de grafites, em São Paulo, pelo prefeito da cidade, Doria. ${ }^{40} \mathrm{O}$ fato foi altamente repercutido e discutido, resultando na produção de novos grafites no local.

Diante desses e de tantos outros eventos e diante das controvérsias geradas por eles, investigamos o fenômeno picho na cidade de Santa Maria/RS e o que ele representa para a sociedade em termos de discurso e organização social. Para isso, esse estudo foi desenvolvido com base na Análise Crítica do Discurso (ACD) para compreendermos o discurso que envolve as práticas de pichação e suas implicações ideológicas.

Durante a organização deste artigo, percebemos que a incidência das manifestações de picho nas imediações de escolas é motivo de registro. Assim, entendemos que essa proposta justifica-se por promover o estudo dos chamados discursos marginais e de uma importante e comum intervenção visual no espaço urbano, que é o picho. Também, pretendemos reforçar estudos sobre a ACD, já que esta surge como um dos caminhos mais reveladores na ciência das Linguagens (WODAK, 2004).

Este artigo estrutura-se em seção de referencial teórico cuja organização constitui-se de duas abordagens: a primeira com uma explanação sobre arte contemporânea e de rua e a segunda, uma discussão sobre a Análise Crítica do Discurso, que perpassa conceitos importantes da dimensão textual, discursiva e social. A metodologia dá conta de apresentar o recorte espacial, os dados e passos da análise. Na seção de resultados, primeiro demos conta de apresentar a análise da dimensão textual (item 4.1), logo, da dimensão discursiva (item 4.2), em seguida, há a discussão da dimensão social (item 4.3) na qual registramos nossa discussão a respeito da representação do picho santa-mariense a partir da investigação das três dimensões.

\section{Referencial teórico}

A arte, o terceiro dos três campos do conhecimento definidos por Aristóteles (1987) (Filosofia, Ciência e Arte) foi encarada de diversas maneiras ao longo do tempo. Vista, inicialmente, como algo racional, a arte passou a ser considerada uma reprodução da realidade, adotou aspectos espirituais de pecado e salvação, buscou o belo, definindo e redefinindo conceitos de estética, construindo e reformulando regras de criação, até chegar à contemporaneidade.

Nesse tempo em que, conforme Bauman (2001), a efemeridade das relações é uma das principais características, os conceitos anteriores de arte no mundo foram contrapostos por uma nova visão de mundo e, consequentemente, de arte. As regras passaram a ser esquecidas, bem como a busca incessante pela beleza. A arte tornou-se meio de crítica social, de expressão da individualidade, de conflitos internos do sujeito e da sociedade. A partir de um desejo, de algumas comunidades, de gritar ao mundo seus conflitos internos para fazê-lo ouvir, na esperança de alguma compreensão e mudança, nasceu a arte de rua, que propõe uma ressignificação de espaços públicos (DJAN, 2015) e é assim que a rua se torna o principal palco dessa manifestação da vida interior.

A arte de rua, também chamada de arte urbana ou marginal, imerge nas cidades e faz de espaços como muros, prédios, calçadas e praças, seu ateliê. Tal fato resulta em um movimento popular que toca desde as classes populares até a elite. Conforme Larruscahim e

\footnotetext{
${ }^{40}$ Fonte Jornal O Globo. Disponível em https://oglobo.globo.com/brasil/doria-apaga-grafites-em-avenida-criapolemica-em-sp-20815081 Acesso em 01/06/2017.
} 
Schweizer (2014), movimentos culturais populares criam estratégias de ajuda e luta coletiva ao problematizarem questões sociais. Assim, a arte urbana, popular, expressa uma crítica social que reflete na diversidade cultural existente na sociedade, por isso, muitas vezes, põe em choque certos valores.

Com isso, as formas de expressão de rua apresentam um caráter subversivo. A arte marginal é exercida, principalmente, por artistas que se encontram à margem do sistema governamental, da sociedade ou dos padrões de conduta pré-estabelecidos, razão esta de sua nomenclatura "marginal". Deste modo, os movimentos de arte de rua também incorporam atitudes transgressoras, das quais muitas são ilegais, seja por promoverem a rebeldia, se apropriarem de espaços particulares ou alterarem a estética de locais públicos (LARRUSCAHIM, SCHWEIZER, 2014).

Contudo, em uma retrospectiva histórica, é possível encontrar diferentes momentos em que certas manifestações artísticas e culturais foram consideradas ilegais, imorais ou afrontas ao discurso dominante. Como afirmam Larruscahim e Schweizer (2014), o próprio samba e a capoeira já foram criminalizados na história de nosso país. Além disso, podemos citar os diversos livros, filmes, peças e músicas censuradas durante a ditadura militar no Brasil. Isso se deve ao fato de a arte ter sido meio de expressão das classes marginalizadas, protestos e reivindicações de direitos desde os séculos anteriores.

A partir da revolução industrial, marco da Modernidade, iniciou-se um intenso processo de êxodo rural e constituição de cidades. Esta urbanização resultou em centros urbanos "fragmentados" e desiguais (SANTOS, 1990). Surgem, então, nessa busca por espaço, as periferias, favelas e a necessidade de se delimitar cada vez mais a propriedade privada com grades e muros. Neste ambiente segregado e desigual, aparecem, também, diferentes movimentos de protesto e busca de maior equidade econômica e social.

Com este intuito, nasceu, na periferia de Nova York, nos anos 1980, o movimento Hip Hop que, com relação às representações gráficas, abriu espaço para os gêneros Grafite e o Picho $^{41}$, manifestações de arte urbana que buscam, por meio de intervenções estéticas em fachadas de propriedades públicas e privadas, acesso à cidade e clamor à sua luta. No Brasil, esses gêneros se disseminaram durante a ditadura militar como a forma encontrada pelo povo para ter voz ativa e lutar por democracia.

O grafite é caracterizado por desenhos grandes, coloridos e arredondados, com uma estética agradável aos olhos da sociedade, trazendo, muitas vezes, uma crítica a ela. Já o picho é mais agressivo, com traços retos e negros, representado por escritas simples com frases impactantes ou, ao contrário, por grifes (símbolos) e tags, assinaturas com grafias altamente elaboradas. Além disso, no que tange ao aspecto jurídico, o grafite é legal no país, enquanto o picho é considerado crime ambiental (LARRUSCAHIM, SCHWEIZER, 2014).

Uma vez que o grafite também é uma linguagem carregada de significados, ideologias e capaz de estabelecer relações de poder, ele se configura como um discurso a ser analisado. O próximo tópico tratará do termo discurso da visão tridimensional do mesmo, proposta por Fairclough (2001).

\subsection{Dimensões do discurso}

O termo discurso é entendido, muitas vezes, como sinônimo de linguagem. Fairclough (2001) o compreende como sendo a linguagem posta em uso. Para o autor, este uso é moldado

\footnotetext{
${ }^{41}$ Entretanto, essa distinção de nomenclaturas, conforme Cargnelutt (2014), ocorre apenas no Brasil. Em outros países, é usado apenas o termo graffiti para se referir às práticas artísticas em questão. Quanto ao aspecto jurídico, apenas no ano de 2011, a prática do grafite passou a ser descriminalizada no Brasil. É agravada, a partir de então, a distinção entre os dois eventos de origem em comum. Ao grafite é atribuída a característica de manifestação artística e cultural, enquanto o picho carrega a imagem de sujo, vândalo, algo que precisa ser combatido (LARRUSCAHIM, SCHWEIZER, 2014).
} 
socialmente e, ao mesmo tempo em que assume uma posição passiva em relação à sociedade, ele também atua sobre ela, sendo capaz de modificá-la de uma maneira global. Deste modo, o discurso desempenha uma relação dialógica com a sociedade. Todo texto produzido contém traços intertextuais de discursos anteriores e influencia os posteriores (BAKHTIN, 1981), respondendo e questionando discursos moldados pela sociedade. Ao passo que se constituem como produtos do contexto, os discursos também o constroem e o significam (FAIRCLOUGH, 2001).

Para Fairclough (2001), o discurso é uma prática constitutiva e construtiva de significação do mundo. Dessa forma, segundo o autor, o discurso constrói "identidades sociais", relações entre membros da sociedade e "sistemas de conhecimento, crença e ideologias". Esse aspecto ativo do discurso é capaz de gerar efeitos nas estruturas de organização social. Contudo, os efeitos dos discursos são combinados com o de outras práticas e não são gerados livremente. A estrutura social molda e orienta o discurso de modo que um atua, ao mesmo tempo, a favor e contra o outro. As diferentes visões ideológicas e políticas é que irão determinar se o discurso convenciona, mantém ou modifica o imaginário social. Assim, as práticas políticas e ideológicas relacionam-se entre si (FAIRCLOUGH, 2001).

Com isso, Fairclough (2001) estabelece uma concepção tridimensional do discurso apresentada na (Figura 1) a partir de Meurer (2005). Os textos, aliados à prática discursiva de produção, distribuição e consumo textual, ambientados em uma prática social mediada por concepções políticas e ideológicas, constituem o discurso.

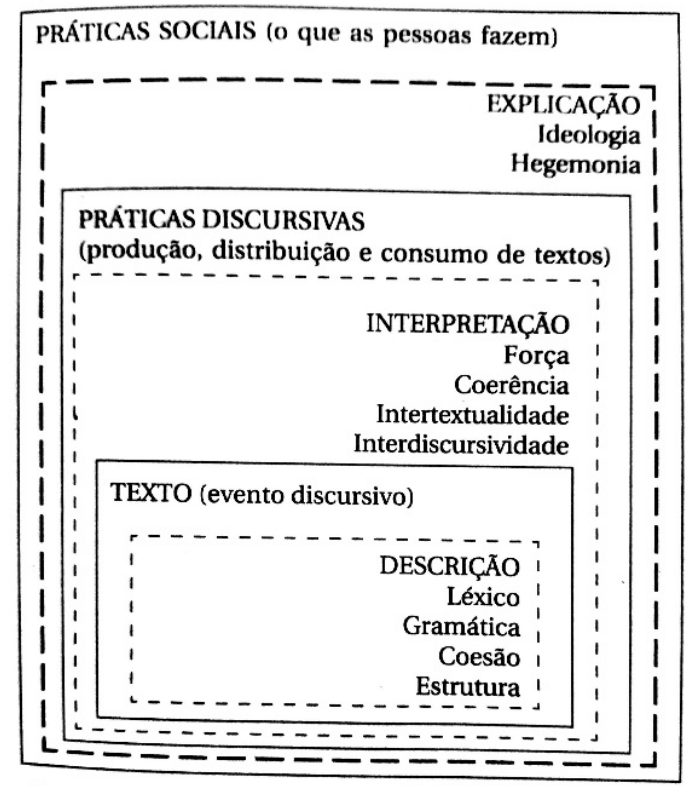

Figura 1 - Representação do modelo tridimensional de Fairclough. Fonte: Meurer (2005, p. 95).

Os textos podem ser analisados, de um modo descritivo, pelos seus aspectos formais e de significados. Fairclough (2001) defende que os significados das palavras são motivados socialmente e, também, que os significados dos textos são passíveis de diferentes interpretações. Isso se deve ao carácter potencial de um texto por se tratar de uma unidade semântica (HALLIDAY, 1989), permitindo visões até mesmo contraditórias sobre ele.

Quanto aos aspectos formais, Fairclough (2001) define quatro itens para a análise: "léxico", "gramática", "coesão" e "estrutura textual". O léxico representa as palavras que se ordenam em frases pela gramática. Essas se organizam pela coesão, constituindo, por fim, o texto em sua estrutura específica. 
Partindo do texto, o autor (2001) elenca três itens para análise da prática discursiva: as "forças dos enunciados", a "coerência" e a "intertextualidade", esta última sendo dividida entre manifesta ou constitutiva/interdiscursividade. Unidos com os quatro itens acima, estes definem o quadro de produção e interpretação de um texto. As diferentes escolhas de estruturas, vocabulários e referências extratextuais resultam em diferentes significados sociais e culturais.

Ainda, fatores sociais também exercem influência sobre o discurso. O contexto definirá o modelo de produção e a forma como o texto será consumido, individual ou coletivamente, registrado ou não, capaz de acarretar grandes atitudes ou ser parcialmente ignorado. Além disso, o contexto conduzirá a forma de distribuição de um texto. Esta poderá ser simples ou complexa, na qual o produtor articula seu texto de modo a prever reações de seus receptores, ouvintes e destinatários (FAIRCLOUGH, 2001).

Tais processos de produção e interpretação são delimitados por normas e convenções sociais, bem como pela natureza particular da prática social (FAIRCLOUGH, 2001). Além disso, os sete itens sociocognitivos de análise de produção e interpretação textuais mencionados anteriormente geralmente são estabelecidos pelo indivíduo de maneira inconsciente e automática, o que contribui para a manutenção ideológica desta prática social, uma vez que não há uma reflexão crítica sobre ela.

A ideologia, assim como o poder, é uma das principais instâncias capazes de constituir, conservar ou transformar o discurso. Fairclough (2001) indica, baseado em Althusser (1971), o caráter institucional da ideologia. Esta, ao reger diferentes esferas da vida social, delimita lutas de classe. Ainda, conforme Althusser (1971), a ideologia confere ao discurso o poder de constituir os sujeitos da prática social.

Os sujeitos, imersos na ideologia, não percebem a dominação desta sobre seus atos. $\mathrm{O}$ indivíduo não compreende que até mesmo as ações mais cotidianas são resultados de investimentos ideológicos promovidos através do discurso. Assim, a naturalização deste leva à falta de criticismo acerca das atividades humanas e, portanto, até mesmo práticas sociais subversivas podem ser realizadas sem o conhecimento da regência ideológica por trás de tais atos.

Como afirma van Dijk (2015), as influências ideológicas são adquiridas por meio de instituições como o Estado, a Igreja, a mídia e a educação. Tais instituições constituem os grupos dominantes e, dessa forma, mediam o discurso ideológico de acordo com seus interesses. Com isso, a sociedade se articula de forma hegemônica, com grupos dominantes e grupos dominados, e são essas relações de poder desiguais que geram significados ideológicos (FAIRCLOUGH, 2001).

Encontram-se, assim, relacionados discurso, poder e ideologia. O poder se estabelece na interação (VAN DIJK, 2015) e, desse modo, depende do discurso para que exista, enquanto a ideologia media e é mediada pelo discurso, bem como pelas relações de poder. Conforme Foucault (1996), a luta pelo poder se dá através do discurso, assim como a constituição ideológica dos sujeitos sociais. Thompson (2011) ressalta que identificar a ideologia é identificar o estabelecimento e a sustentação de relações de dominação, hegemonia, por meio dos sentidos construídos através do discurso.

A fim de que se mantenha a hegemonia, é exercido um controle da prática discursiva. A produção de certos gêneros de discurso não é permitida de forma global à sociedade, assim como são restringidas, também, as distribuições e o consumo dos mesmos (VAN DIJK, 2015). A informação é transformada em mercadoria e reconhecida a uma pequena parcela da população, responsável pela manipulação que ocorre, muitas vezes, sobre a parcela desinformada e doutrinada da sociedade.

O acesso ao capital, ao conhecimento e ao status fornece subsídios para o que van Dijk (2015) chama de "elites simbólicas". Estas, compostas por políticos, professores, empresários, 
advogados e etc., possuem o poder de moldar a mente, o discurso e as ações daqueles os quais dominam. Contudo, como afirma o autor, até mesmo estas elites são guiadas pela ideologia das instituições às quais pertencem.

Desse modo, estes grupos possuem uma liberdade restrita e, por isso, seus interesses podem entrar em conflito com o das instituições. Um conflito ideológico, adjunto com um relativo poder sobre as práticas sociais e discursivas de outros indivíduos, pode acarretar um ato de resistência contra a ideologia dominante. Tais atos podem provocar uma mudança discursiva (FAIRCLOUGH, 2001) por meio da transgressão do discurso vigente e da democratização de um discurso rearticulado em prol das categorias dominadas (VAN DIJK, 2015).

\section{Metodologia}

Este estudo tem caráter interpretativo-analítico, uma vez que ele objetiva compreender as representações discursivas presentes no picho e seu aspecto veiculador de ideologia e poder. Os procedimentos metodológicos usados passaram pelos processos de observação dos excertos linguísticos, descrição, interpretação e explicação das ocorrências, conforme modelo tridimensional. Desse modo, a ACD é a abordagem adotada tanto como teoria quanto método para a análise linguístico-discursiva do corpus selecionado.

O corpus de análise deste estudo foi composto por oito pichações (Anexo 1), coletadas por meio de levantamento fotográfico feito pela própria pesquisadora. Para facilitar a organização da análise, os textos foram arranjados por códigos. A fim de identificar os exemplares em análise e referi-los ao longo do estudo, o código de cada picho inicia por $\mathrm{P}$ (referente a picho), seguido por sustenido (\#) e, logo, do número de identificação (de 1 a 8 ). $\mathrm{O}$ número limitado de textos justifica-se pela natureza qualitativa deste estudo, pelo tempo limitado para conclúi-lo e pelo fato de esta ter sido uma análise para exercitar e colocar em prática alguns critérios de análise da $\mathrm{ACD}$, não pretendendo, assim, estender discussões.

Como recorte espacial, definimos o bairro Centro da cidade de Santa Maria/ RS e bairros do entorno, a saber: Bonfim, Itararé, Menino Jesus, Nonoai, Nossa Senhora das Dores, Nossa Senhora de Fátima, Nossa Senhora de Lourdes, Nossa Senhora do Perpétuo Socorro, Nossa Senhora do Rosário, Nossa Senhora Medianeira. Os motivos para escolher essas regiões se dão porque, primeiro, não seria viável, pelo tempo limitado deste estudo, analisar pichações em toda a cidade; segundo, porque a região central é onde há uma grande circulação de pessoas, de todas as regiões da cidade, e onde as vozes "marginais" podem ganhar destaque; e, terceiro, porque algumas destas regiões abrigam manifestações típicas de arte de rua, como, por exemplo, a Praça João Pedro Menna Barreto, mais conhecida como Praça dos Bombeiros, no bairro Bonfim, onde ocorre a Batalha de Hip Hop. Como recorte temporal para a coleta dos dados, definimos entre os meses de abril a julho de 2017.

Quanto ao tratamento dos dados, analisamos os oito textos a partir do modelo tridimensional do discurso, proposto por Fairclough (2001, p. 101). Dessa maneira, para que pudéssemos atingir nosso objetivo central, os passos de análise foram:

(a) identificação da dimensão textual por meio do mapeamento e descrição dos itens lexicais e da estrutura textual ${ }^{42}$.

(b) verificação da dimensão discursiva por meio da análise da produção, distribuição e consumo e da aplicação de critérios como força dos enunciados, coerência, intertextualidade e interdiscursividade;

\footnotetext{
42 O critério de análise "coesão", proposto para análise da dimensão textual pela ADC, foi eliminado da metodologia, pois os pichos constituem-se de apenas uma oração, sendo, desse modo, um critério que nos daria pouco ou nenhum resultado.
} 
(c) exame da dimensão da prática social por meio da análise e explicação de questões relativas à ideologia e poder.

O passo "a" foi desenvolvido a partir do dicionário Michaelis, de conhecimentos da gramática brasileira e da análise semântica; o passo " $b$ " foi desenvolvido, principalmente, a partir de Fairclough (2001), e o passo "c" desenvolvido, principalmente, a partir de Fairclough (2001) e Van Dijk (2015). Esses passos foram seguidos no intuito de responder à questão norteadora deste estudo - que representações discursivas se revelam no picho da região central da cidade de Santa Maria/RS?

\section{Resultados}

Nessa seção, primeiro demos conta de apresentar a análise da dimensão textual (item 4.1), logo, da dimensão discursiva (item 4.2), em seguida, há a discussão da dimensão social (item 4.3) na qual registramos nossa discussão a respeito da representação do picho santamariense a partir da investigação das três dimensões.

\subsection{Dimensão Textual - mapeamento e descrição dos itens lexicais e da estrutura textual}

Nessa seção, seguem os exames dos significados lexicais e da estrutura textual, conforme o dicionário Michaelis, de conhecimentos da gramática brasileira e da análise semântica.

Em P\#1, a frase "Não vote, se revolte!" apresenta os termos principais "votar" e revoltar". "Votar" provem do latim e significa eleger alguém por meio do voto, enquanto "revoltar" se caracteriza por "incitar à revolta ou à insurreição; amotinar(-se), subvelar(-se), causar ou sentir indignação ou repulsa". Nesse sentido, em um mesmo campo lexical, são agrupados termos que denotam a necessidade de mudança, de atitudes proativas.

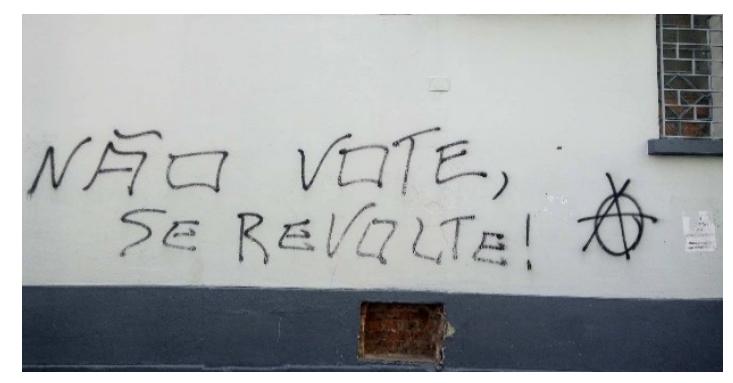

Figura 2 - $P \# 1^{43}$

Em P\#1, a primeira oração da frase "Não vote" possui a intenção de gerar uma mudança provocada pelo sujeito "você". O verbo "vote" indica ação explícita e, devido a esse fato de representar uma mudança em uma esfera política já constituída, essa oração é transformativa. Na segunda oração, "se revolte", o verbo revoltar-se exprime um significado relativo à percepção da realidade, expressa um grau de afeição, pelo fato de a oração ser uma ordem de revoltar a si próprio e a sua atitude frente ao sistema político. A frase é constituída por duas ordens, ou seja, a pessoa falante leva o seu interlocutor a realizar duas ações, expressando o que quer que ele faça.

Em P\#2, a frase "Fora Temer", possui a interjeição "fora", uma exclamação que indica ordem para sair. O nome próprio "Temer" (sobrenome do atual presidente da república, que

\footnotetext{
${ }^{43}$ Rua Roque Callage. Bairro Centro.
} 
assumiu o cargo no ano de 2016 após o impeachment de Dilma Rousseff) indica um substantivo próprio já conhecido pela população brasileira. A hashtag \#ForaTemer inundou as redes sociais e, na semana seguinte ao impeachment de Dilma, decretado em 31 de agosto de 2016, as ruas foram tomadas pela frase em análise; em pouco tempo, essa ordem saiu das redes sociais e tornou-se comum em muros e paredes de todo o país.

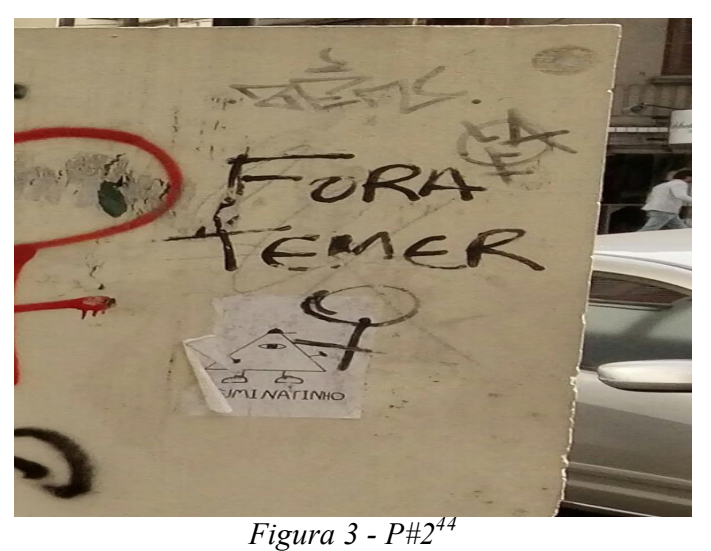

Semelhante ao P\#2, em "Fora estado burguês" (P\#3), é apresentado, novamente, "fora", interjeição que indica ordem para sair. Aqui, o termo "estado" representa o regime político atual, e "burguês" pode ser encarado como um adjetivo histórico de alguém que pertencente ao burgo, relativo ao indivíduo da classe média e alta. Estado Burguês, na teoria marxista (BOUCHER, 2015), é aquele pelo qual a burguesia exerce o poder político através de uma determinada combinação de instituições políticas, além de ser a classe dominante na sociedade, classe essa que procura manter vivas convenções já há muito estabelecidas. No Brasil, o termo estado burguês faz referência à ordem política de direita. Desse modo, nesse contexto, essa ordem de saída ("fora") aos políticos de direita encontra no picho um espaço de interação com a comunidade.

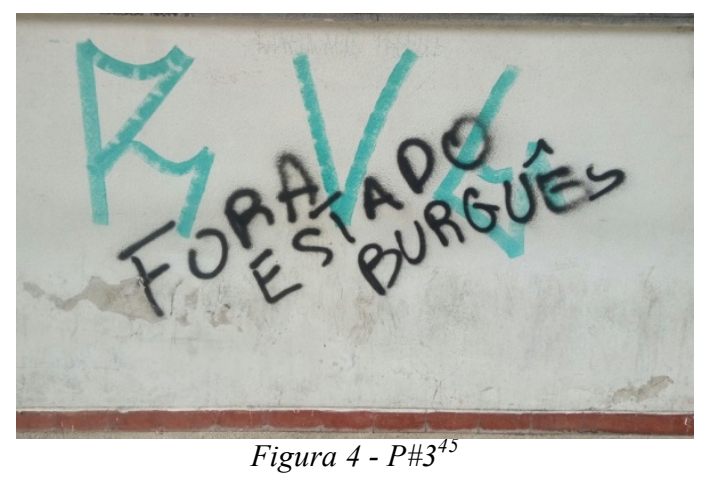

Em P\#4, a frase "Chupa minha xereka!" possui o verbo "chupar" que significa extrair (líquido) com a boca ou levar à boca por meio de sucção. Há um segundo termo vulgar, "xereka", para se referir à vulva, conjunto dos órgãos sexuais externos femininos. Termos como "chupar" e "xereca", nitidamente vulgares vêm ao encontro do que permite o picho. Esses termos poderiam ser, claramente, inadequados para muitos textos que circulam em espaços públicos. Contudo, como foi publicado em um picho, eles ganham, justamente pelo gênero textual, um nível de valor entre os usuários do gênero visto que este é um espaço de subversão de regras e de normalidades. Ainda, P\#4 apresenta um

\footnotetext{
${ }^{44}$ Rua Cel. Niederauer, Bairro Bonfim.

${ }^{45}$ Rua Serafim Valandro, bairro Centro.
} 
verbo indicativo de comportamento fisiológico humano ("chupa"). Com isso, a autora do picho (presume-se que seja autora) busca, por meio de uma ação físiológica, uma mudança de paradigmas, um rompimento de convenções já estabelecidas às mulheres.

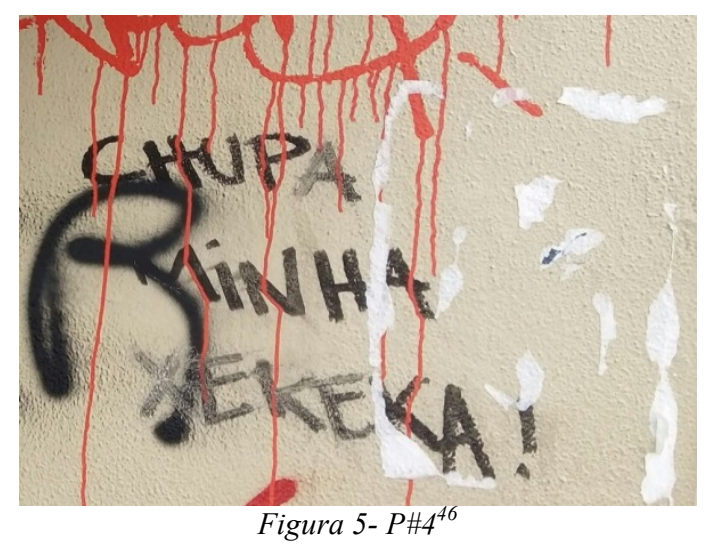

Seguindo o levantamento lexical, em P\#5, a frase "Vulva la revolucion" apresenta-nos o termo "vulva", conjunto dos órgãos sexuais externos femininos. Nesse exemplar, esse item lexical vem acompanhado do termo "revolucion" ("revolução"), que carrega o significado do efeito de revolucionar(-se), de realizar mudanças profundas ou radicais, ou, ainda, de transformação radical de padrões culturais. "Vulva lá revolucion" é um trocadilho com a já conhecida frase "Viva a revolução". Nesse contexto (P\#5), vulva, termo representativo da expressividade feminina, tomou o lugar de viva indicando uma busca pelo empoderamento e emancipação das mulheres.

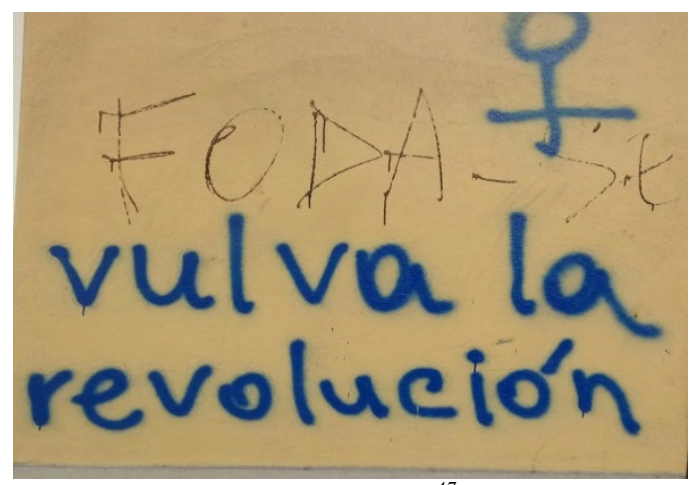

Figura $6-P \# 5^{47}$

Enquanto isso, a frase "Respeita as mina!" (P\#6) é organizada pelo verbo "respeitar" que diz respeito a reverenciar, demonstrar consideração por alguém. Esse alguém, nesse contexto, são "as mina", termo coloquial, usado, principalmente, por grupos de falantes jovens e que faz referências às meninas. Em P\#6, percebemos um incentivo à mudança de percepção referente ao que é sentido ou pensado na consciência do indivíduo. Portanto, temos um verbo abstrato no indicativo de cognição (respeitar) e não ação propriamente dita. Com isso, há uma ordem que propõe uma nova visão das "minas", mulheres em geral.

\footnotetext{
${ }^{46}$ Rua Cel. Niederauer, 1527, bairro Bonfim.

${ }^{47}$ Rua Silva Jardim, bairro Nossa Senhora do Rosário.
} 


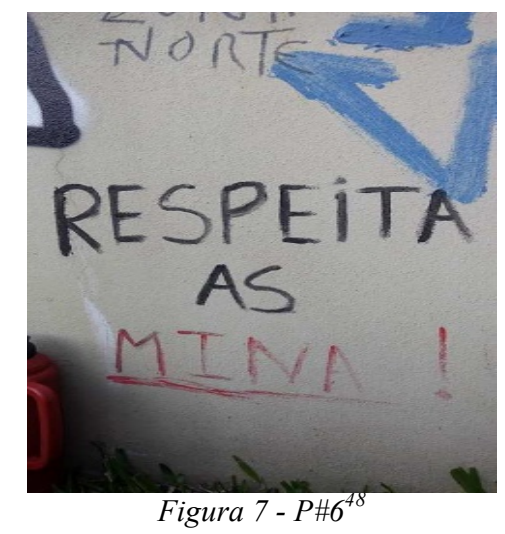

Com relação à análise lexical de $\mathrm{P} \# 7$, em "Vai ter cota", há o verbo "ter" significando estar na posse ou gozo de algo, desfrutar, gozar, possuir, usufruir. Além disso, o substantivo "cota" diz respeito à parte ou quantia de um todo. No âmbito educacional, cota é a reserva de vagas em concursos para negros, indígenas e brancos de famílias de baixa renda e egressos de escolas secundárias públicas. Nesse sentido, "ter" junto à "cota" implica uma busca por desfrutar uma parte de um todo (vagas) que, claramente, é necessária para manter a igualdade no sistema de ensino público e superior. Ainda, com relação à frase "Vai ter cota" (P\#7), temos uma oração que marca a existência de algo, pelo verbo "ter" no sentido de "existir", mas, pela frase estar se referindo ao futuro, ela trata da existência de algo ainda a se esperar.

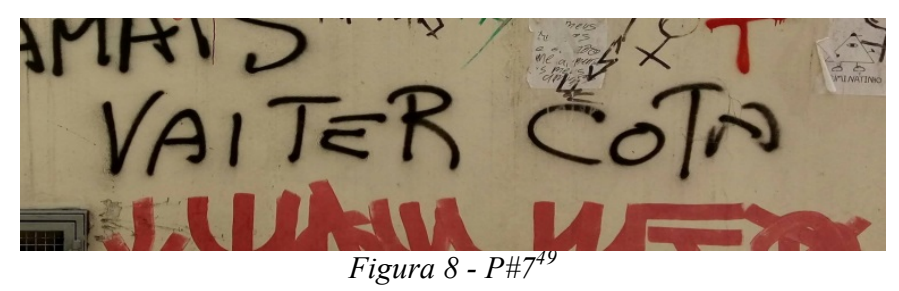

Em P\#8, "Educação não é mercadoria", há dois termos essenciais, "Educação" e "Mercadoria". Educação é entendida como o processo de desenvolvimento físico, intelectual e moral do ser humano que lhe assegure integração social e formação da cidadania, ela não é um produto a ser comercializado, comprado, vendido ou negociado. Já "mercadoria" é um termo que quer dizer um bem que pode ser objeto de compra e venda, e incita benefício ou lucro a alguém. Esses dois termos opostos estão conectados em um mesmo texto e fazem uma crítica às instituições privadas de ensino. Essa crítica fica evidente pelo local onde ele foi publicado - muro de uma das maiores escolas particulares de educação básica da cidade. Ainda, ao ser estabelecida uma relação entre dois termos, o item "Mercadoria" é, aqui, uma qualidade ao termo "Educação", o que constitui uma oração de relação, que marca a definição de conceitos, características e de crenças do pichador.

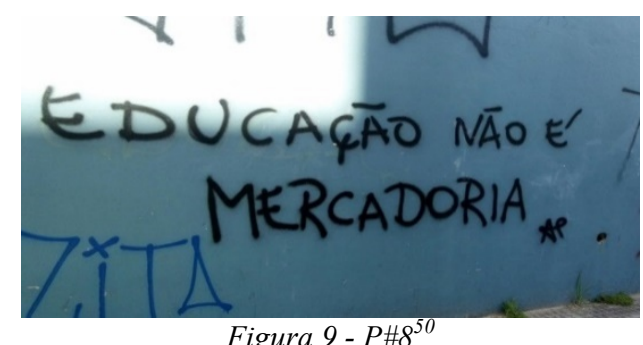

Figura 9 - $P \# 8^{50}$

\footnotetext{
${ }^{48}$ Rua Tuiuti, bairro Centro.

${ }^{49}$ Rua Cel. Niederauer, bairro Bonfim.

${ }^{50}$ Rua Serafim Valandro, bairro Centro.
} 
Esse primeiro passo de análise demonstrou a recorrência de palavras de ordem, gírias, termos revolucionários e uma crítica social. Tal fato coloca a pichação como um texto produzido por grupos marginais que buscam uma mudança, uma reinvindicação de espaço e de direitos.

\subsection{Dimensão Discursiva - produção, distribuição, consumo, força dos enunciados, coerência, intertextualidade e interdiscursividade}

Conforme Fairclough (2001), a análise da prática discursiva focaliza os processos de produção, distribuição e consumo textual. No caso do picho, os textos são produzidos de forma rápida devido ao risco (por questões legais) que o produtor corre ao produzi-lo. Deste modo, são, em sua maioria, textos curtos, frases prontas pensadas anteriormente pelo pichador (proposições já definidas).

Ainda, no contexto específico da pichação, ocorre, já no momento de produção, o processo de distribuição. Ao contrário de outros textos, o picho, tão logo é distribuído ao público, este se distribui aos arredores dos pichos. Os diferentes locais onde os pichos se encontram constituem a distribuição, efetuada no ato de produção. Ainda, a escolha destes locais pode abrigar um significado velado a ser interpretado no momento do consumo, como no exemplo de P\#8, encontrado nos muros de uma escola privada de Santa Maria.

Quanto ao consumo, há uma grande diversidade de consumidores potenciais da pichação, portanto o impacto gerado pode ser bastante variado. Como os exemplares foram todos coletados na região central da cidade, o consumo abarca um enorme número de pessoas e há a possibilidade de diferentes grupos acessá-los, pois entendemos por centro urbano a região mais ativa de uma cidade, onde se concentra a atividade comercial e financeira e onde pessoas de qualquer região da cidade se concentram.

Além dos processos de produção, distribuição e consumo, para a análise da prática discursiva, Fairclough (2001) propõe a análise da força dos enunciados, da coerência e da intertextualidade manifesta ou constitutiva/interdiscursividade. A força dos enunciados se refere à ação social que o texto realiza, o ato de fala que expressa seu significado interpessoal.

Desse modo, P\#2, P\#3 e P\#5, orações nominais, contêm as interjeições "fora" (P\#2 e $\mathrm{P \# 3)} \mathrm{e} \mathrm{"vulva"} \mathrm{(P \# 5)} \mathrm{(no} \mathrm{sentido} \mathrm{de} \mathrm{"viva").} \mathrm{Interjeições,} \mathrm{segundo} \mathrm{Ferreira} \mathrm{(2007),} \mathrm{têm} \mathrm{a}$ força de expressão intensa de certos sentimentos e emoções, o que ocorre fortemente em representações artísticas. Já, as frases P\#7 e P\#8 constituem uma troca de informações através de proposições. Assim, a função destas é de declaração e o recurso gramatical utilizado para estabelecer uma interação é o declarativo, fato que complementa o objetivo do pichador de alertar.

Os demais pichos, $\mathrm{P} \# 1, \mathrm{P} \# 4$ e P\#6, apresentam uma solicitação em forma de proposta. Com isso, a função desses textos é de um comando expresso pelo modo imperativo. Nestas, não há uma troca de informação, mas uma busca por troca ações. As declarações reforçam a construção dos sistemas de conhecimento e crença (Fairclough, 2001), ideologia, que se deseja, enquanto as palavras de ordem orientam as ações a serem tomadas a partir destes sistemas.

Em relação à coerência, Fairclough (2001) a considera como uma propriedade das interpretações. Assim, segundo o autor, um texto apenas possui sentido para alguém que a ele infere algum sentido. Deste modo, a coerência referente ao picho depende da capacidade do indivíduo de compreendê-los e relacioná-los com determinados pressupostos. Tais conexões são subsidiadas pela ideologia do sujeito e possibilitam, portanto, diferentes leituras de mesmos textos. Então, se misturam e se combinam discursos no ato da interpretação dos pichos. Com isso, o consumo destes textos adota um aspecto intertextual que também se 
aplica aos processos de produção e distribuição, uma vez que a ideologia dos produtores também é constituída por uma conexão de discursos.

A intertextualidade, conforme Fairclough (2001), pode ser manifesta ou constitutiva, esta também chamada de interdiscursividade. A primeira ocorre quando há alguma referência explícita a outro texto. Contudo, os pichos adotados para análise apresentam apenas a intertextualidade constitutiva (interdiscursividade). Este conceito se refere à realização de diferentes enunciados em um texto.

Com base nisso, o exemplar P\#1 realiza intertextualidade constitutiva com o discurso político. Após inúmeros escândalos de corrupção na mídia, alternância de diferentes partidos no poder e a consequente descrença no sistema político do país, o texto busca negar esse sistema e propõe a revolução, a partir de uma mudança de percepção da política.

$\mathrm{P} \# 2$ é outro picho que realiza diálogo com o discurso político. O texto faz alusão ao presidente da república Michel Temer que assumiu o cargo após o processo de impeachment de Dilma Roussef. O caso foi tema de bastante debate, no qual muitos ainda defendem o caráter golpista deste processo ${ }^{51}$.Além disso, o índice de aprovação de Temer é o mais baixo para presidente desde $1986^{52}$.

P\#3 faz intertextualidade constitutiva com o discurso político, histórico e social. Uma vez que o termo "estado" pode significar o modo com algo se encontra; a condição emocional psicológica ou moral de uma pessoa e, ainda, um regime político, ele se relaciona tanto com a política como com a organização da sociedade e do imaginário de cada indivíduo. Ainda, o termo "burguês" faz referência a contextos históricos onde burguês era alguém que pertencia ao burgo. Hoje, ressignificado, esse termo se refere a alguém conservador, contra mudanças que vive de acordo com convenções. Assim, ao utilizar a interjeição "fora", esse picho refuta a organização da sociedade, da política e do indivíduo como algo estático e conservador. Ele utiliza a união dos três discursos para incitar uma mudança geral no modo como as coisas se encontram.

Já o P\#4 faz intertextualidade com o discurso feminista. Por muito tempo a sexualidade feminina foi ignorada e, até mesmo censurada. Hoje, na busca pela rearticulação do discurso sexual de modo a incluir o prazer feminino como uma das prioridades do sexo, esse picho comanda uma ação do leitor ao quebrar o tabu de se falar em sexo. Além disso, ele apresenta o termo vulgar "xereka" para, de fato, escrachar a natureza cotidiana do ato sexual.

P\#5 intercala o discurso revolucionário de esquerda com o feminista. O picho faz referência à frase "Viva a revolução", bastante presente em contextos subversivos. Contudo, ele enfatiza a importância das mulheres neste cenário historicamente masculino. Ainda, ao ressaltar como tema da oração o órgão sexual feminino, também reforça o valor a ser dado à sexualidade feminina.

O exemplar P\#6 é outro texto que engloba o feminismo em seu discurso. Em um país onde, segundo o Fórum Brasileiro de Segurança Pública, uma mulher é estuprada a cada 11 minutos $^{53}$, a busca por respeito e direitos torna-se luta de inúmeras mulheres. Portanto, esse picho estabelece um comando direcionado ao leitor para que mude sua percepção em relação ao sexo feminino.

O exemplar P\#7, por sua vez, representa as minorias em geral no discurso. É uma afirmação de que negros, portadores de deficiência, estudantes de escola pública e pessoas

\footnotetext{
${ }^{51}$ Fonte Jornal do Brasil. Disponível em:

http://www.jb.com.br/pais/noticias/2017/08/31/impeachment-contra-dilma-rousseff-completa-1-ano-neste-31-deagosto/ Acesso em 09/11/2017.

${ }^{52}$ Fonte G1. Disponível em:

http://g1.globo.com/jornal-nacional/noticia/2017/09/aprovacao-de-temer-e-mais-baixa-para-presidente-desde1986-diz-ibope.html Acesso em 09/11/2017.

${ }^{53}$ Fonte jornal El País. Disponível em:

https://brasil.elpais.com/brasil/2017/02/01/opinion/1485962834_237097.html Acesso em 26/10/2017.
} 
com baixa renda possuam condições mais equitativas de passarem em concursos e processos seletivos. Ele reafirma a necessidade de políticas públicas que ajudem a compensar as injustiças sofridas por essas minorias ao longo do tempo.

Por outro lado, P\#8 relaciona o discurso escolar com o empresarial. Nesta conexão, o texto se apropria do discurso escolar e nega o segundo. Esse picho, encontrado na fachada de uma escola particular do centro de Santa Maria, retrata a transformação da educação em um produto oferecido por determinadas instituições. Assim como todo produto, a educação, deste modo, está disponível somente para aqueles que conseguem pagar o preço dela, colocando-a, assim, em uma posição elitista, razão de privilégios. Neste contexto, esse picho refuta a visão mercantil do saber e declara a necessidade de uma educação de qualidade a todos.

\subsection{Dimensão Social - ideologia e poder}

O discurso como prática social é capaz de estabelecer, manter ou modificar relações de poder, além de constituir, manter ou transformar sujeitos e significados do mundo (FAIRCLOUGH, 2001). Tais capacidades são inferidas ao discurso pelo seu conteúdo ideológico e hegemônico capaz de guiar a mente e as ações humanas a partir do diálogo.

É pelo diálogo que se forma a mente humana (BAKHTIN, 2003). O diálogo com diferentes enunciados e discursos molda mentes e as mentes controlam a ação. Em outras palavras, é pelo discurso que se constitui a ideologia e esta, por meio do discurso, constitui os sujeitos da prática social (ALTHUSSER, 1971) e as ações exercidas por estes.

Conforme Fairclough (2001), as características do uso da linguagem podem ser determinadas pelas relações entre classes sociais. Tais relações geram significados ideológicos e estabelecem um modelo hegemônico de sociedade. $\mathrm{O}$ picho, assim como a linguagem da cultura hip-hop em geral, problematiza as contradições sociais e traz à tona novas formas de pensar em busca de identidades sociais marginalizadas (SOUZA, 2011). No seio das relações entre as classes, ele representa as classes dominadas em seu discurso.

Com isso, percebe-se um conflito ideológico entre o discurso vigente e o discurso da pichação. A presença de interjeições indicando ordem para sair, os processos transformativos e o léxico referente a minorias são alguns exemplos de como a prática da pichação pretende uma mudança social a partir da mudança discursiva. Além disso, a linguagem da pichação ajuda a construir sujeitos ideologicamente capazes de estabelecer uma luta hegemônica por meio de troca de informações e de palavras de ordem que guiam as ações dos consumidores.

Para que se mantenha um sistema hegemônico, é exercido o controle da prática discursiva por meio das instituições e da mercantilização do saber. O poder controla o discurso público, os meios de produção discursiva e, assim, também controla a mente do público. Quem está no topo da cadeia hegemônica decide quem pode falar e escrever, sobre o quê e para quem. Desse modo, a falta de poder leva a falta de informação e ao silenciamento (VAN DIJK, 2015).

Os pichos em análise, mesmo sendo considerados crimes, não se sujeitam ao controle discursivo. Eles não estão, diretamente, ligados a instituições e, assim, conseguem rebater a ideologia expressa por elas. Ao se apropriarem de suas fachadas, de modo subversivo e revolucionário, eles invadem o local onde se articulam discursos hegemônicos e se formam ideologias para rearticular o discurso dominante em prol das minorias.

Ainda, uma vez que a ideologia se encontra presente nas diversas manifestações econômicas, políticas e artísticas, uma mudança nas ordens de discurso nesses âmbitos acarreará um ato de resistência e, portanto, de luta hegemônica. Desse modo, os pichos em análise, ao praticarem mudanças discursivas, imergem em outras esferas sociais e adquirem a força de resistência e luta contra as relações de poder naturalizadas ao longo do tempo. 


\section{Considerações finais}

Após concluir o percurso que nos propomos realizar, cumpre-nos fazer um balanço do trabalho desenvolvido e avaliar a sua pertinência. Para compreendermos o discurso que envolve as práticas de pichação e suas implicações ideológicas, buscamos fazer um mapeamento e descrição dos itens lexicais e da estrutura textual dos exemplares. Esse passo mostrou-nos que os itens lexicais usados para constituir os pichos demonstram campos lexicais voltados a palavras de ordem, a reconstruções políticas, às forças de grupos minoritários e à busca por igualdade entre os sexos, ou seja, formas de expressão da rua que apresentam um caráter subversivo.

Após isso, a partir da discussão da dimensão discursiva, verificamos que os pichos são dialógicos com questões sociais em pauta. Tais diálogos são marcados por enunciados efetivamente ligados ao campo discursivo político, educacional e social. Esses discursos são deslocados para o campo discursivo do picho, e, por se encontrarem materializados nesse gênero, cuja função principal é a de servir de crítica social e resistência, acabam desqualificando os textos a eles anteriormente publicados (picho sendo diálogo), fatos políticos e sociais, gerando o efeito de subversão a partir de enunciados categóricos e enérgicos, ou seja, a interação entre produtor e leitor é baseada na ordem.

Por fim, o exame da dimensão social consolidou nossa percepção de que o picho, enquanto prática social, representa uma manifestação cultural e pode ser percebido como um vetor para comportamentos que buscam quebrar expectativas e padrões consolidados. O picho pode ser considerado um fenômeno dinâmico, não linear, e com um papel importante para a construção de novos comportamentos e crenças e para o empoderamento de grupos minoritários.

A análise feita nesse estudo, leva-nos, então, a consolidar o picho como um gênero textual que busca uma mudança social. Por meio do diálogo entre a ação social do picho e as ordens de discurso nele presentes, é realizada a problematização de questões, em sua maioria, políticas e de gênero. o picho, expressão artística subversiva e transgressora, rearticula discursos naturalizados estabelecendo uma luta hegemônica. Assim, ele provoca uma mudança discursiva que implica em novas concepções ideológicas e em diferentes relações de poder para, assim, atingir uma mudança social. Essa mudança visa à democratização de espaços, discursos e direitos.

Ao tomar posse de propriedades públicas e privadas, a prática da pichação desafia instituições e torna seu discurso acessível a um público que varia desde as classes populares até a elite. Ainda, após a análise realizada, foi possível perceber, nesse discurso, a defesa das minorias e o foco em construir sujeitos ideologicamente capazes de realizar mudanças a partir de suas ações.

Limitamo-nos, aqui, e entendemos haver lacunas deixadas pelo estudo, pelo pouco tempo de pesquisa e pelo número restrito de exemplares - foi desaconselhável analisar um grande número de pichos, já que a maioria nos daria respostas semelhantes e os resultados poderiam ficar exaustivos. Por último, parece-nos conveniente que estudos futuros deem conta de analisar outras questões pertinentes ao picho, como uma análise mais profunda dos contextos sociais (o que não deu tempo nessa etapa) e de recursos semióticos como cores, tipo de fonte, etc. 


\section{REFERÊNCIAS}

ALTHUSSER, L. Ideology and ideological state apparatuses. In: Althusser, L. (ed.) Lenin and philosophy and other essays. Londres: New Left Books, 1971.

ARISTÓTELES. Organon - V - Tópicos. Lisboa: Guimarães editores, 1987.

BAKHTIN, M. The dialogical imagination. Holquist, M. (ed.), trad. C. Emerson and M. Holquist. Austin: University of Texas Press, 1981.

Estética da criação verbal. 4. ed. São Paulo: Martins Fontes, 2003.

BAUMAN, Z. Modernidade Líquida. Rio de janeiro: Zahar, 2001.

BOUCHER, G. Marxismo. São Paulo: Editora Vozes, 2015

CARGNELUTT, G. A identidade cultural dos pichadores de Santa Maria/RS. Trabalho final de graduação. Curso de Publicidade e Propaganda do Centro Universitário Franciscano. Santa Maria, 2014.

DJAN, C. A criminalização da pixação. Revista Vaidapé, v. 4, p. 44-49, 3 de Junho de 2015. Disponível em: http:/vaidape.com.br/2015/06/a-criminalizacao-da-pixacao/. Acesso em 15 de maio de 2017.

FAIRCLOUGH, N. Discurso e mudança social. Brasília: Editora Universidade de Brasília, 2001.

FERREIRA, M. Aprender e praticar gramática - Ed. Renovada. São Paulo: FTD, 2007. HALLIDAY, M.A.K.; HASAN, R. Language, context, and text: aspects of language in a social-semiotic perspective. New York: Oxford Press, 1989.

LARRUSCAHIM, P. G.; SCHWEIZER, P. A criminalização da pixação como cultura popular na metrópole brasileira na virada para o século XXI. R. Dir. Gar. Fund., Vitória, v. 15, n. 1, p. 13-32, jan./jun. 2014.

MEURER, J.L. Gêneros textuais na análise crítica de Fairclough. In: MEURER, J.L.;

BONINI, A.; MOTTA-ROTH, D. Gêneros - teorias, métodos, debates. São Paulo: Parábola, 2005.

SANTOS, M. Metrópole corporativa e fragmentada. O caso de São Paulo. São Paulo: Nobel, 1990.

SOUZA, A. L. S. Letramentos de reexistência: poesia, grafite, música, dança: HIP-HOP. São Paulo: Parábola Editorial, 2011.

THOMPSON, J. B. Ideologia e cultura moderna: teoria social crítica na era dos meios de comunicação em massa. 9 ed. Petrópolis, RJ: Vozes, 2011.

VAN DIJK, T. A. Discurso e Poder. 2.ed. São Paulo: Contexto, 2015.

WODAK, R. Do que trata a ACD - um resumo de sua história, conceitos importantes e seus desenvolvimentos. Revista Linguagem em (Dis)curso - LemD, Tubarão, v. 4, p. 223-243, 2004. Disponível em: http://linguagem.unisul.br/paginas/ensino/pos/linguagem/linguagemem-discurso/0403/040310.pdf. Acesso em: 18 jun. 2017. 